\title{
The Use of Nanofibers in the Clothing Industry
}

\author{
Roman Knížek* \\ Department of Textile Evaluation, Czech Republic
}

ISSN: 2578-0271

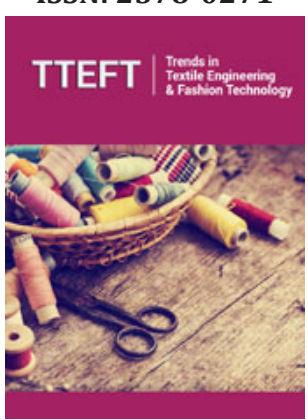

*Corresponding author: Roman Knizek, Department of Textile Evaluation, Technical University of Liberec, Czech Republic

Submission: 侮 March 05, 2019

Published: 佔 May 07, 2019

Volume 5 - Issue 1

How to cite this article: Roman Knižek. The Use of Nanofibers in the Clothing Industry. Advancements Bioequiv Availab.5(1). TTEFT.000602.2019.

DOI: 10.31031/TTEFT.2019.05.000603.

Copyright@ Roman Knizek, This article is distributed under the terms of the Creative Commons Attribution 4.0 International License, which permits unrestricted use and redistribution provided that the original author and source are credited.

\begin{abstract}
These days, nanofiber layers are used not only for filtration and separation purposes, but also in the clothing industry. Nanofiber membranes are highly suitable for this purpose because of their high porosity, which is $25 \%$ higher than the porosity of common porous PTFE membranes, and which provides much better water vapor permeability than other membranes available on the market.
\end{abstract}

Keywords: Nanofiber membrane; Nanofiber; Outdoor

Membrane for use in the Clothing Industry

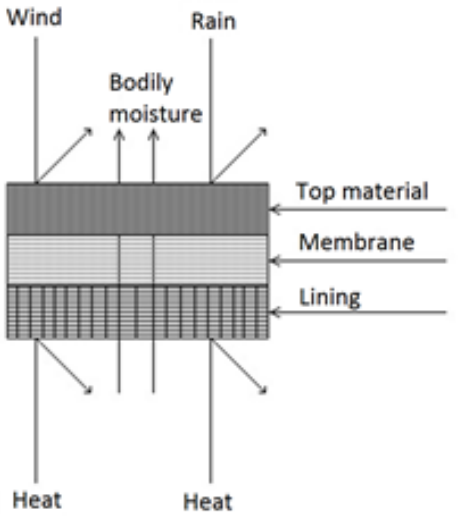

Figure 1: The membrane function diagram.

In Figure 1 you can see how such a nanofiber membrane for clothing works. Drops of water (snow, rain) fall on the top surface material. The top material tries to stop these drops from getting under this textile. This top material is often impregnated or has some chemical finish to achieve this, but at the same time it must be able to let water vapor through. This top material with its good properties has also got its limits and that's why a nanofiber membrane is added. The different materials (woven or knitted textile and nanofiber membrane) are laminated together to form 2-layer, 2.5-layer or 3-layer laminates. The membranes are made of polymers, the most common ones being PTFE (Polytetrafluoroethylene), PES (Polyether sulfone) or PUR (Polyurethane). The membrane thickness is in the range of micrometer units [1-3].

\section{Nanofiber Membrane Development}

A Nano spider machine was used to produce the nanofiber membrane (Figure 2). Polyurethane polymer was chosen because it is easy to use on a Nano spider machine, but also for its elasticity as it gives the final laminate sensibility that is very desirable in some kinds of closing.

The produced nanomembrane is made hydrophobic using Fluorocarbon type C6 monomer in low vacuum plasma to achieve a higher hydrostatic resistance. The hydrostatic resistance can be more than $20000 \mathrm{~mm}$ depending on the top material laminated to the membrane. After hydrophilization the nanomembrane is laminated together with other textile materials. Many long-term tests have shown that a 3-layer laminate is the only 
solution for nanofiber layers as these layers are very susceptible to friction and for that reason must be well protected on both their sides by other textile materials laminated onto them. (Figure 3) shows such a 3-layer laminate.

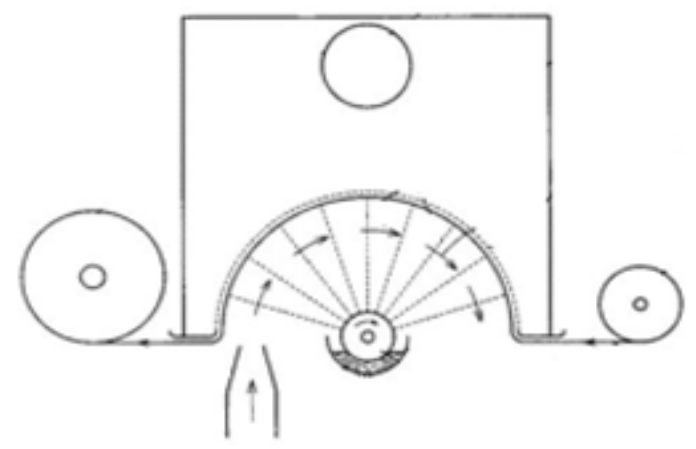

Figure 2: The Nano spider machine for the production of nanofibers by electrospinning [4].

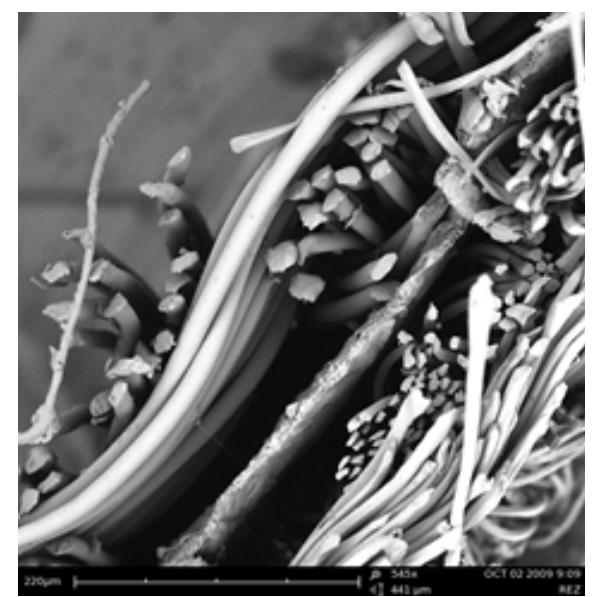

Figure 3: 3-layer laminate cross-section.

Result

Table 1.

\begin{tabular}{|c|c|c|c|}
\hline & 2-layer Laminate & 3-layer Laminate & $\begin{array}{l}\text { 3-layer Laminate with PTFE } \\
\text { Membrane (Gore-Tex) }\end{array}$ \\
\hline $\begin{array}{l}\text { Water vapor permeability [Pa. } \\
\qquad \mathrm{m} 2 / \mathrm{W}]\end{array}$ & 1 & 1.6 & 2.5 \\
\hline $\begin{array}{c}\text { Air permeability }[\mathrm{l} / \mathrm{m} 2 / \mathrm{s}] \text { at } \\
100 \mathrm{~Pa} \text { pressure }\end{array}$ & $<3$ & $<2$ & 0 \\
\hline Hydrostatic resistance[mm] & 6000 & $>10000$ & $>10000$ \\
\hline
\end{tabular}

Table 1 shows the results for 2-layer and 3-layer laminates with a nanofiber membrane and a 3-layer laminate from the Gore-Tex company (with the same areal weight).
a) Top layer: 100\% PES, 80gsm, ripstop weave
b) Membrane: 100\% PU, 3gsm
c) Lining: $100 \%$ PES, 66gsm, weft-knit fabric
d) Gore-Tex: Active

The results show, that the nanofiber layer laminate has a much higher water vapor permeability than the laminate with a Gore-Tex membrane while at the same time both laminates have a similar hydrostatic resistance. The nanofiber membrane shows a slightly higher air permeability, but the value is insignificant with respect to the material's function. All laminates are $100 \%$ windproof.

\section{References}

1. Roey M V (1992) Water-resistant breathable fabrics. Journal of Industrial Textiles 22: 20-31.

2. Ahn HW, Park Ch H, Chung SE (2011) Waterproof and breathable properties of nanoweb applied clothing. Textile Research Journal 81(14): 1438-1447. 
3. Gorji M, Jeddi AA, Gharehaghaji AA (2012) Fabrication and characterization of polyurethane electro spun nanofiber membranes for protective clothing applications 125(5): 4135-4141.
4. Růžičková J (2004) Electrospinning nano fibers. Technical University of Liberec, Czech Republic.

For possible submissions Click below:

\section{Submit Article}

